\title{
Carbonation Resistance of Reinforced Concrete under Bending Load
}

\author{
Yan Liu \\ Tianjin University, Key Laboratory of the Ministry of Education on Binhai Civil Engineering Structure and Security, Tianjin \\ 300072, China \\ Hebei Construction Group Corporation Limited, Baoding 071000, China \\ College of Urban and Rural Construction, Agricultural University of Hebei, Baoding 071001, Cbina \\ liuyan7521@126.com
}

\section{Jun Ren}

College of Urban and Rural Construction, Agricultural University of Hebei, Baoding 071001, Cbina

1375733149@qq.com

\section{Zhongxian Li}

Tianjin University, Key Laboratory of the Ministry of Education on Binhai Civil Engineering Structure and Security, Tianjin 300072, China

zxli@tju.edu.cn

\author{
Qiuli Gao \\ Hebei Construction Group Corporation Limited, Baoding 071000, China \\ Gao8089@163.com
}

\section{Shengli Zhao}

College of Urban and Rural Construction, Agricultural University of Hebei, Baoding 071001, China

zhaovictory@163.com

\begin{abstract}
Fly ash has been used more and more often to take the place of cement as the admixture of concrete in the construction of concrete buildings. However, with the increase of the carbon dioxide $\left(\mathrm{CO}_{2}\right)$ concentration in the atmosphere, carbonization damage has become an essential factor affecting the durability of fly ash concrete. Here a long-term bending load device was developed to explore how the pouring surface and the bending load affect the carbonization resistance of reinforced concrete under rapid carbonization. In addition, the relationship between the bendingtension and bending-compression loads with respect to the carbonization damage of test blocks was also investigated. Due to the differences in the concrete compactness, the carbonization depth of the pouring surface was
\end{abstract}

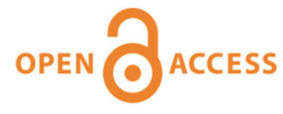

Citation: Liu, Y., Ren, J., Li, Z.X., Gao, Q., Zhao, S.L., Carbonization resistance of reinforced concrete under bending load, Frattura ed Integrità Strutturale, 49 (2019) 714-724.

Received: 24.04 .2019 Accepted: 13.06.2019 Published: 01.07.2019

Copyright: (C) 2019 This is an open access article under the terms of the CC-BY 4.0, 
found to be greater than that of the bottom at the same position. To a certain extent, with the increasing bending-load stress, different carbonization resistances were observed in the bending-tension zone and the bendingcompression zone of the concrete test blocks. Meanwhile, to study the relationship between the carbonization damages in the bending-tension zone and the bending-compression zone of concrete test blocks, a carbonization influence coefficient of bending tension-compression load was proposed, which provides a convenient and scientific guidance for the detection and evaluation of concrete carbonization damages in practical engineering.

KEYwORDS. Reinforced concrete; Bending load; Pouring surface; Carbonization depth; Carbonization influence coefficient of bending tensioncompression load. which permits unrestricted use, distribution, and reproduction in any medium, provided the original author and source are credited.

\section{INTRODUCTION}

he replacement of cement with fly ash as the admixture of concrete can not only reduce cement consumption but also effectively improve various properties of concrete [1-3]. Therefore, fly ash has been used more and more widely in concrete buildings. On the other hand, due to the deterioration of the natural environment and the increase of the $\mathrm{CO}_{2}$ concentration in the atmosphere, carbonization damage has become one of the most significant factors affecting the durability of fly ash concrete. However, the effect of load on the carbonization resistance of fly ash concrete was rarely discussed [4-10]. In practical engineering, the structure of a building is subject to the combined action of both load and environment, especially the former, so studying the environment alone cannot fully solve the carbonization problem in practical engineering [11-15]. Most of the building components such as beams and slabs are mainly subjected to the bending load in concrete structures. So the carbonization analysis under bending loads is still the focus of the durability study on fly ash concrete. However, the current research conclusions cannot be directly compared as they were obtained from different experimental platforms. What is more, most of the research focused on plain concrete, without considering the influence of steel bars on its carbonization, which cannot provide very helpful reference for the actual engineering, as studies [16-18] have shown that steel bars make the concrete more compact on the setting and hardening process of the concrete, which inhibits the carbonization damage of the concrete. This paper performed a rapid carbonization test to investigate how the bending load affects the properties of reinforced concrete blocks with varying fly ash contents. Then it analyzes the effects of the pouring surface and the bending tension and compression loads on the carbonization resistance of concrete and the relationship between the tension and compression loads with respect to their effects on the carbonization resistance of concrete. Furthermore, it proposed a carbonization influence coefficient of bending tension-compression load with respect to reinforced concrete. In summary, this study can provide convenient and scientific guidance for the detection and evaluation of carbonization damages in concrete structures in practical engineering.

\section{EXPERIMENT}

\section{Experimental materials}

$\mathrm{P}$ .O 42.5 ordinary Portland cement and Grade II fly ash (type F) were used in the experiment. River sand was used as fine aggregate, with a fineness modulus of 2.74 and good gradation. The continuously graded crushed stone with a particle size of $5-20 \mathrm{~mm}$ was adopted as coarse aggregate. In this experiment, polycarboxylates highperformance water reducing admixture was adopted. The strength of the concrete blocks was C30, and four fly ash contents (the mass ratio of fly ash) were selected, namely, $0 \%, 20 \%, 30 \%$ and $40 \%$. The concrete mix proportions are listed in Tab. 1. The test blocks were divided into several groups, each of which contains 51 blocks. In each group, 3 blocks were subjected to the measurement of ultimate bending load, and 48 underwent the carbonization test. 


\begin{tabular}{cccccccccc}
\hline Number & $\begin{array}{c}\text { Fly ash } \\
\text { content }\end{array}$ & $\begin{array}{c}\text { Cement } \\
(\mathrm{Kg})\end{array}$ & $\begin{array}{c}\text { Fly ash } \\
(\mathrm{Kg})\end{array}$ & $\begin{array}{c}\text { Sand } \\
(\mathrm{Kg})\end{array}$ & $\begin{array}{c}\text { Stone } \\
(\mathrm{Kg})\end{array}$ & Sand rate & $\begin{array}{c}\text { Water } \\
(\mathrm{Kg})\end{array}$ & W/B & Water-reducer \\
$\mathrm{A}$ & $0 \%$ & 373.63 & 0 & 682.87 & 1114.16 & $38 \%$ & 179.34 & 0.48 & $0.40 \%$ \\
$\mathrm{~B}$ & $20 \%$ & 298.90 & 74.73 & 682.87 & 1114.16 & $38 \%$ & 179.34 & 0.48 & $0.46 \%$ \\
$\mathrm{C}$ & $30 \%$ & 261.54 & 112.09 & 682.87 & 1114.16 & $38 \%$ & 179.34 & 0.48 & $0.52 \%$ \\
$\mathrm{D}$ & $40 \%$ & 224.18 & 149.45 & 682.87 & 1114.16 & $38 \%$ & 179.34 & 0.48 & $0.56 \%$ \\
\hline
\end{tabular}

Table 1: Concrete mix proportions

\section{Experimental method}

Preparation of test blocks: $100 \mathrm{~mm} \times 100 \mathrm{~mm} \times 300 \mathrm{~mm}$ rectangular concrete test blocks were used in the experiment. The reinforcement diagram of a test block is shown in Fig. 1.
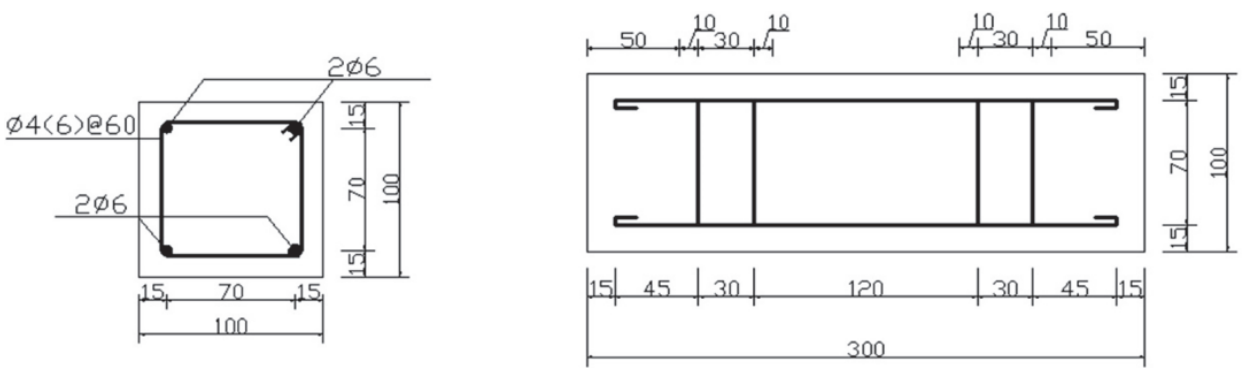

Figure 1: Reinforcement diagram of the reinforced concrete block

Load device: A long-term bending-load device was developed in the experiment by reference to the other load devices [16-17, 19-24]. As shown in Fig. 2, the device consists of two screws with a diameter of $12 \mathrm{~mm}$, eight nuts, four shims and a steel column support. If two torque wrenches are used to twist the nuts at the same time and with the same speed to produce a tightening force, the screw will bear tension, forming pressure on both sides of the block, thereby exerting bending load on the test block. The bending tension load generated on the side of the block away from the support is defined as the tension surface, while the bending compression load generated on the side of the block near the support is called the compression surface. In this experiment, the compression load is directly applied on the pouring surface. The bending load stress of the block can be adjusted by using the torque wrench to apply the torque. This loading strategy is highly reliable, as evidenced by its extensive application in the research of concrete durability under bending stress.
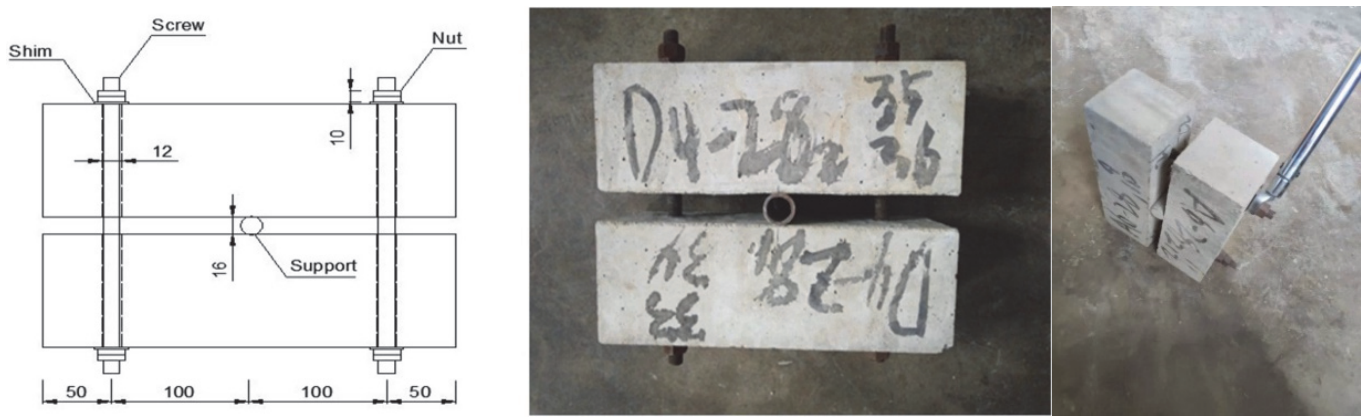

Figure 2: Long-term bending-load device

\section{Experimental procedure}

The three-point bend loading test was first performed on the concrete blocks using a universal testing machine. The ultimate bending load $F$ (i.e. the pulling force of the screws at both ends of each block) of the three blocks in each mix ratio were measured separately on the universal testing machine. To ensure the reliability of measured results, the average value was taken as the final $F$ value of reinforced concrete under this mix ratio. The corresponding $F$ was $37.88 \mathrm{kN}, 33.16$ $\mathrm{kN}, 34.18 \mathrm{kN}$ and $32.04 \mathrm{kN}$ when the fly ash content of the test blocks was $0 \%, 20 \%, 30 \%$ and $40 \%$.

Each group of test blocks were loaded with $0 \%, 20 \%, 40 \%$ and $60 \%$ of the ultimate bending load based on the formula $T=K \cdot F \bullet D[25]$ ( $T$ is the torque magnitude; $K$ is the torque coefficient, which was set to 0.19 ; and $D$ is the screw diameter, 
which was set to $12 \mathrm{~mm}$ ). The carbonization experiments were carried out on the reinforced concrete test blocks with four mix proportions under long-term bending load.

The carbonization test was carried out in the standard fast carbonation box in the laboratory. The environmental parameters in the carbonization box include $\mathrm{CO}_{2}$ concentration of $(20+3) \%$, relative humidity of $(70+5) \%$, and temperature of $(20+2){ }^{\circ} \mathrm{C}$. The concrete blocks were carbonized for three different periods, namely, 7,14 and 28 days. During the test, the concrete blocks were put into the carbonization box and carbonized to the corresponding period. After that, they were taken out for the measurement of carbonation depth. Specifically, each test block was split along the mid-span direction, and phenolphthalein, $1 \% \mathrm{w} / \mathrm{v}$ in alcohol, was dripped evenly on the block surface with a rubber head dropper. The carbonized part of the block did not change color, while the non-carbonized part became purple red. According to the change of cross-section color, the carbonation depths at 9 points were measured within $60 \mathrm{~mm}$ in the middle of tension zone and the compression zone, and the average value was taken as the final carbonization depth of the area.

To prevent the stress loss of the long-term load device, two preventive measures were taken in this experiment:

(1) The pre-tension was carried out before the bending load was applied. First, a torque which was 1.05-1.1 times the corresponding stress was applied to the test block for $2-5 \mathrm{~min}$, and then the load was removed and the corresponding torque was applied.

(2) During the carbonization process, the applied torque was measured every 7 days and any reduction of torque would be compensated.

\section{RESULTS AND DISCUSSION}

\section{Effect of the pouring surface on the carbonization resistance of concrete}

T $\mathrm{n}$ the experiment, the carbonization depths of each block were measured from four longitudinal sides, and it was found that the carbonization depths were different from different sides, showing the different carbonization resistances of the concrete. Through analysis, it was found that the carbonization resistances of the pouring surface (top surface) and the non-pouring surface (bottom surface) were different. Some literatures [26-30] have found that the segregation of concrete during vibration lead to the unevenness of the block from the top to the bottom, and that the pouring surface of the concrete in actual construction has a certain effect on the carbonization resistance of concrete. To compare the difference in the carbonization performance between the pouring surface and the non-pouring surface, the carbonization influence coefficient of the pouring surface, denoted as $K$, is defined as follows:

$$
K=\frac{X_{p}}{X_{b}}
$$

where $X_{p}$ is the carbonization depth of the pouring surface (top surface) while $X_{b}$ is the carbonization depth of the nonpouring surface (bottom surface).

With the data in Tab. 2, the variation curve of the carbonization influence coefficient $K$ of the pouring surface with different fly ash contents can be determined (as shown in Fig. 3).

As shown in Fig. 3, $K$ decreased as the carbonization period increased. In the first 14 days, the decreasing rate was relatively fast, while in the subsequent 14 days, the declining trend became relatively gentle. In addition, the value of $K$ was always greater than 1 . This shows that the carbonization speed of the pouring surface was greater than that of the bottom surface under the same mix proportion. As both the top and the bottom were reinforced in the same way, the difference in the carbonization depth might be caused by the different compactness of the top and the bottom surfaces of the concrete. Therefore, the cross sections of the concrete test blocks were selected and the tops and the bottoms of the cross sections were observed, as shown in Fig. 4.

As indicated in Fig. 4, the top of the cross section showed less coarse aggregate and denser pores, compared to the bottom of the test block. In addition, there was a thin layer of mortar at the top of the block. Due to the gravity and vibration when the block was poured and vibrated, the cohesion between the cement paste and the aggregate was not enough to resist against the external vertical downward force acting on the aggregate, so the heavy aggregate would sink and the light cement slurry would float. As a result, there was an increase in the coarse aggregate and a decrease in the cement paste from top to bottom along the cross section of the block. The water-to-cement ratio at the top became larger and that at the bottom smaller. There were more capillary pores and larger cracks at the top in comparison with those at 
the bottom. This suggests that the compactness at the top is worse than that at the bottom. Through measurement of the electric flux at the tops and bottoms of other test blocks, it was also noticed that the electric flux at the top was much larger than that at the bottom [26], further proving the widespread phenomenon of higher permeability at the tops of the concrete blocks after setting and hardening. As a result, $\mathrm{CO}_{2}$ can more easily and rapidly enter and erode the inner part of the block from the top. Furthermore, the carbonization depth at the top was greater than that at the bottom, so the coefficient $K$ was greater than 1 . However, when the carbonization depth reached a certain value, the closer the central carbonization zone of the cross section was, the smaller the difference in the concrete compactness would be. Thus, the carbonization depths at the top and bottom would be closer, making the curve change more gently.

\begin{tabular}{ccccc}
\hline $\begin{array}{c}\text { Fly ash } \\
\text { content }\end{array}$ & Coefficient & \multicolumn{3}{c}{ Carbonization depth/ mm } \\
& $X_{p}$ & 4.74 & 5.48 & 7.94 \\
0 & $X_{b}$ & 4.50 & 5.34 & 7.93 \\
& $K$ & 1.05 & 1.03 & 1.00 \\
\hline \multirow{3}{*}{$20 \%$} & $X_{p}$ & 7.13 & 8.71 & 9.58 \\
& $X_{b}$ & 5.40 & 7.20 & 8.26 \\
& $K$ & 1.32 & 1.21 & 1.16 \\
\hline \multirow{3}{*}{$30 \%$} & $X_{p}$ & 7.61 & 8.76 & 9.98 \\
& $X_{b}$ & 5.90 & 7.30 & 8.60 \\
& $K$ & 1.29 & 1.20 & 1.16 \\
\hline \multirow{3}{*}{$40 \%$} & $X_{p}$ & 8.00 & 9.25 & 10.63 \\
& $X_{b}$ & 6.20 & 7.84 & 9.75 \\
& $K$ & 1.29 & 1.18 & 1.09 \\
\hline
\end{tabular}

Table 2: Carbonization depths of the pouring and bottom surfaces of concrete $/ \mathrm{mm}$

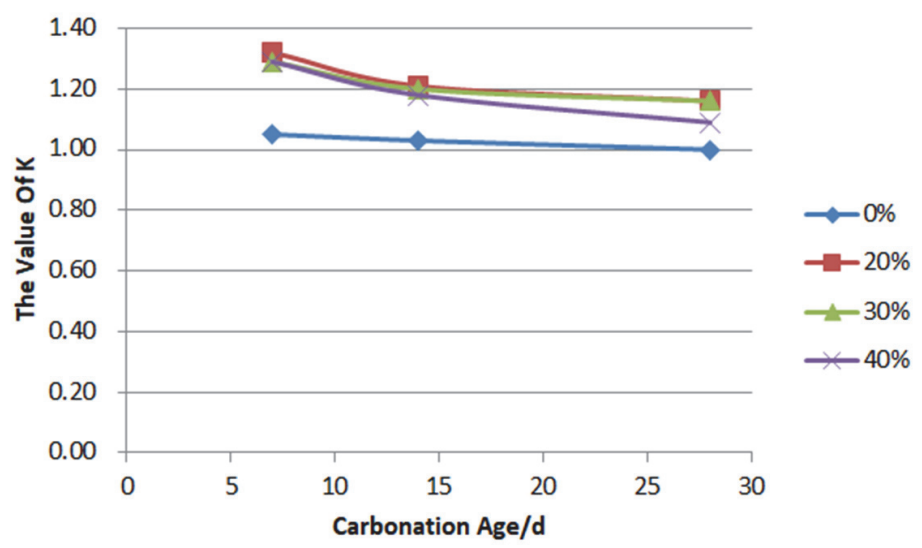

Figure 3: Curve of the carbonization influence coefficient $\mathrm{K}$ of the pouring surface at different fly ash contents
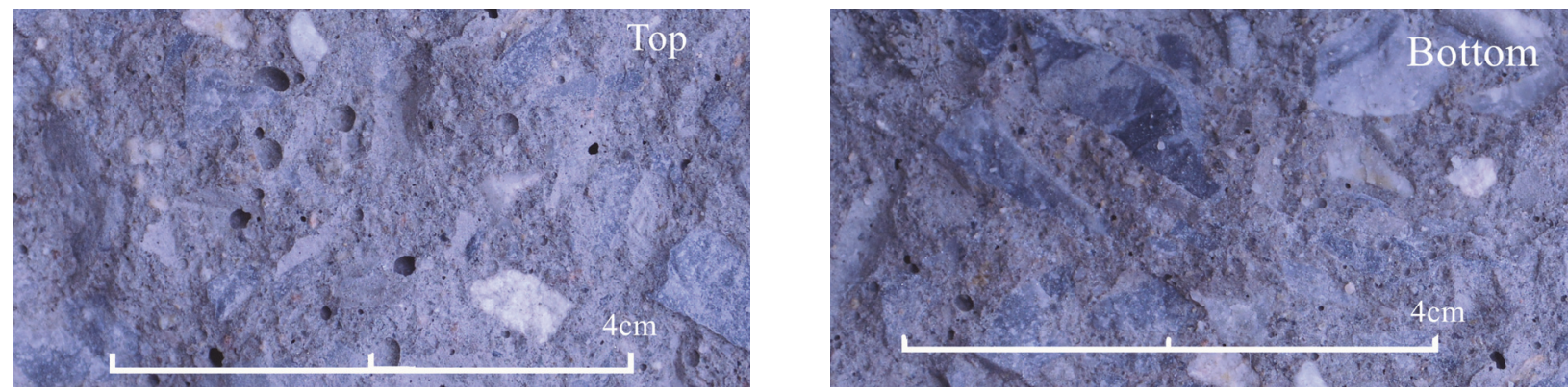

Figure 4: Comparison between the top and bottom surfaces of the concrete test blocks

As shown in Fig. 3, the $K$ values of the blocks without fly ash were always lower than those of the blocks with fly ash. When the blocks are vibrated, the fluidity and segregation of the cement paste will increase under the action of shaking 
table and vibrating rod, that is, the "shear-thinning" feature in fluid dynamics. Fly ash is a microscopic particle whose shape is similar to a globule. However, the shapes of cement particles are irregular. Therefore, when fly ash is added into the cement paste (with a fly ash content of less than 50\%), the friction of cement mortar will be reduced under the rolling effect. Since less water is needed for the smooth surface of the fly ash sphere, the free water in the mortar will increase, diluting the cement mortar and increasing the shear thinning degree [31]. As a result, when the fly ash concrete is vibrated and the density difference between the top and the bottom becomes larger, the course aggregate moves downward faster.

\section{Effect of bending load on the carbonization resistance of concrete}

The carbonization depths of the reinforced concrete blocks in the bending-tension and bending-compression zones under different bending loads are shown in Tab. 3.

\begin{tabular}{ccccc}
\hline $\begin{array}{c}\text { Fly ash } \\
\text { content }\end{array}$ & $\begin{array}{c}\text { Bending load stress } \\
\text { level }\end{array}$ & $\begin{array}{c}7 \mathrm{~d} \\
\text { Tension/compre } \\
\text { ssion }\end{array}$ & $\begin{array}{c}14 \mathrm{~d} \\
\text { Tension/compre } \\
\text { ssion }\end{array}$ & $\begin{array}{c}28 \mathrm{~d} \\
\text { Tension/compre } \\
\text { ssion }\end{array}$ \\
& $0 \%$ & $4.74 / 4.50$ & $5.48 / 5.34$ & $6.64 / 7.93$ \\
$0 \%$ & $20 \%$ & $4.56 / 5.99$ & $5.32 / 6.54$ & $6.25 / 9.65$ \\
& $40 \%$ & $4.01 / 7.32$ & $4.88 / 8.56$ & $5.33 / 10.28$ \\
& $60 \%$ & $3.55 / 8.86$ & $4.21 / 9.77$ & $4.56 / 11.26$ \\
\hline \multirow{2}{*}{$20 \%$} & $0 \%$ & $7.13 / 5.40$ & $8.71 / 7.20$ & $9.58 / 8.26$ \\
& $20 \%$ & $6.02 / 7.55$ & $6.57 / 8.38$ & $8.23 / 9.95$ \\
& $40 \%$ & $5.55 / 7.92$ & $6.26 / 8.78$ & $7.05 / 11.45$ \\
$30 \%$ & $60 \%$ & $4.55 / 9.57$ & $5.32 / 10.95$ & $5.88 / 12.50$ \\
& $0 \%$ & $7.61 / 5.90$ & $8.76 / 7.30$ & $9.98 / 8.60$ \\
& $20 \%$ & $6.87 / 7.99$ & $8.76 / 9.26$ & $9.35 / 9.98$ \\
& $40 \%$ & $6.74 / 8.45$ & $7.44 / 9.87$ & $8.05 / 12.00$ \\
$40 \%$ & $60 \%$ & $5.52 / 9.85$ & $6.38 / 11.20$ & $7.52 / 12.98$ \\
\hline & $0 \%$ & $8.00 / 6.20$ & $9.25 / 7.84$ & $10.63 / 9.75$ \\
& $20 \%$ & $7.50 / 8.24$ & $9.24 / 10.24$ & $10.25 / 12.99$ \\
& $40 \%$ & $6.85 / 9.57$ & $8.82 / 10.55$ & $10.01 / 13.21$ \\
& $60 \%$ & $6.02 / 10.45$ & $7.22 / 11.98$ & $9.00 / 13.90$ \\
\hline
\end{tabular}

Table 3: Carbonization depths of concrete test blocks under different bending loads $/ \mathrm{mm}$

\section{Effect of bending-compression load on the carbonization resistance of concrete}

The variation curve of the carbonization depth in the bending-compression zone of concrete with the bending load stress level is shown in Fig. 5.

Fig. 5 shows that with the bending load stress increasing, the carbonization depth of the concrete in the bendingcompression zone decreased under the same fly ash content. This indicates that the bending-compression load inhibits the erosion of $\mathrm{CO}_{2}$ and improves the carbonization resistance of concrete.

To quantify the effect of bending load stress on the carbonization depth of concrete blocks, the carbonization influence coefficient of bending-compression load stress was used, by reference to Niu Jiangang's method [16].

$$
K_{c}=\frac{X_{c}}{X_{n}}
$$

where $K_{c}$ is the carbonization influence coefficient of bending-compression load stress; $X_{c}$ is the carbonization depth of concrete under bending load in the compression zone; and $X_{n}$ is the carbonization depth of concrete without load in the compression zone.

Through regression analysis, the fitting equation between the carbonization influence coefficient of bending-compression stress and bending load stress level under different fly ash contents can be determined, as shown in Tab. 4, where $K_{C}$ is the carbonization influence coefficient of bending-compression stress and $S_{C}$ is the bending load stress level.

As shown in Tab. 4, the relationship between the carbonization influence coefficient of the bending-compression stress and the bending load stress level can be described using a quadratic polynomial. The coefficient of this formula is different from the results of the quadratic polynomial fitting in reference [16]. The main reason may be that the 
experimental materials in the reference were plain concrete blocks and that the research did not consider the effect of steel bars. In actual practice, the steel bars affect not only the concrete compactness but also the transmission channels of $\mathrm{CO}_{2}$ in the concrete and enlarge the stiffness of the components, affecting the carbonization resistance of concrete.
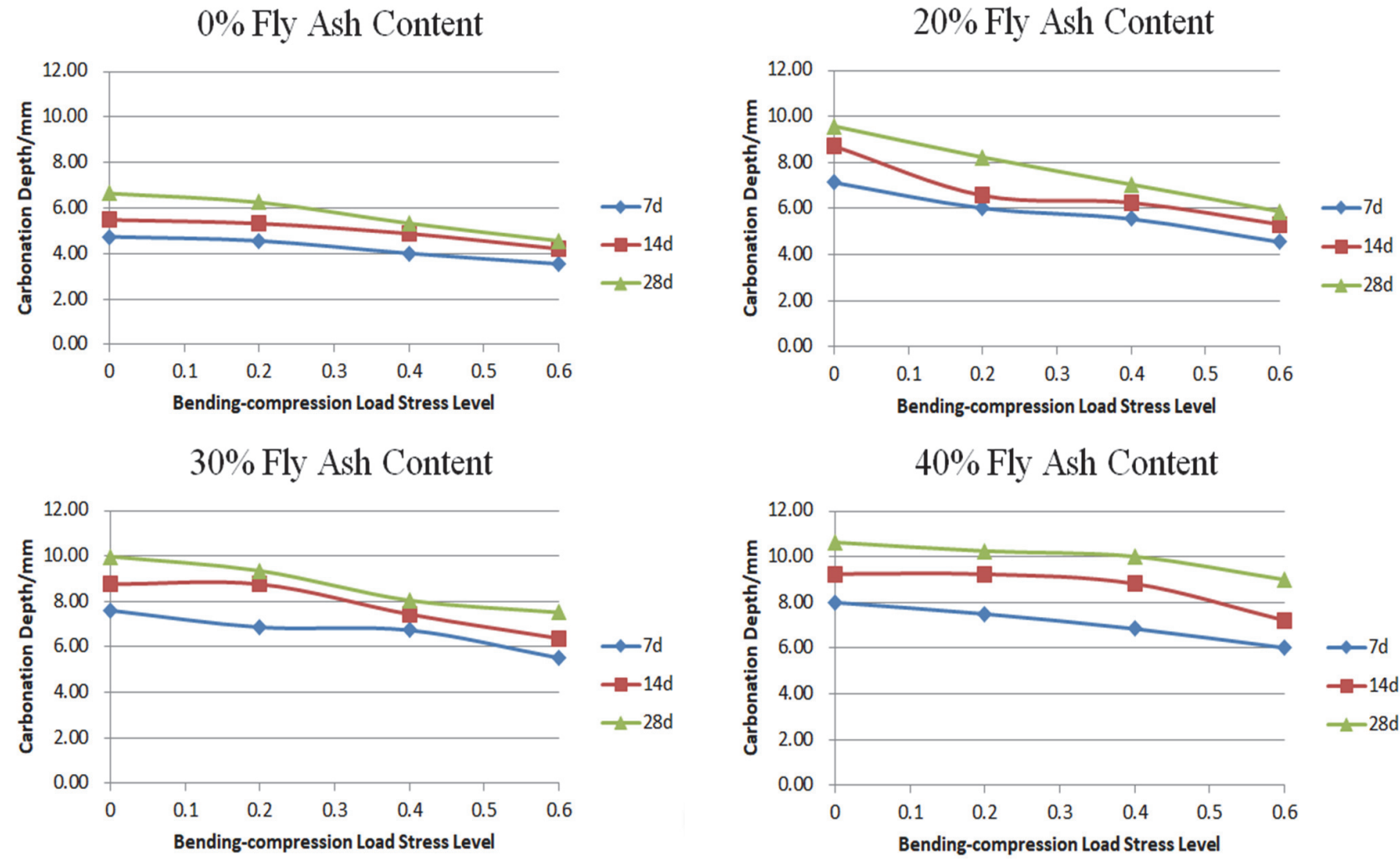

Figure 5: Relationship between carbonization depth in the concrete compression zone and bending-compression load stress level in different carbonation periods

\begin{tabular}{ccc}
\hline $\begin{array}{c}\text { Fly ash } \\
\text { content }\end{array}$ & Fitting equation & Correlation coefficient \\
$0 \%$ & $K_{C}=-0.4326 S_{c}^{2}-0.1921 S_{c}+1.0035$ & 0.99 \\
$20 \%$ & $K_{C}=0.3583 S_{c}^{2}-0.8211 S_{c}+0.9923$ & 0.99 \\
$30 \%$ & $K_{C}=0.3626 S_{c}^{2}-0.2285 S_{c}+1.0017$ & 0.98 \\
$40 \%$ & $K_{C}=-0.5675 S_{c}^{2}+0.0055 S_{c}+0.9971$ & 0.99 \\
\hline
\end{tabular}

Table 4: Equation of the carbonization influence coefficient of bending-compression stress

However, when the bending-compression stress increases to a certain extent, the concrete in the compression zone will be almost crushed and the carbonization damage will increase dramatically. Therefore, the carbonization influence coefficient of bending-compression stress is only applicable within the range of $0 \%$ to $60 \%$ of the ultimate bending stress level.

\section{Effect of bending-tension load on the carbonization performance of concrete}

Fig. 6 shows the analysis of the carbonization depth of concrete with different fly ash contents in the bending-tension zone with the bending load stress level.

As shown in Fig. 6, the carbonization depth of concrete increased with the increase of the bending load stress level under all four conditions. The bending-tension stress promoted the entry of $\mathrm{CO}_{2}$ into the concrete and aggravated the carbonization damage of concrete in the tension area.

To quantify the effect of bending-tension stress on concrete carbonization, the carbonization influence coefficient of bending-tension stress is defined as follows: 


$$
K_{t}=\frac{X_{t}}{X_{n}}
$$

where $K_{t}$ is the carbonization influence coefficient of bending-tension stress, $X_{t}$ the carbonization depth of concrete under bending load in the tension zone; and $X_{n}$ the carbonization depth of concrete without any load in the tension zone.

Through regression analysis, the equation describing the carbonization influence coefficient of bending-tension stress and bending load stress level under different fly ash contents is shown Tab. 5, where $K_{t}$ is the carbonization influence coefficient of bending-tension stress and $S t$ the bending load stress level.
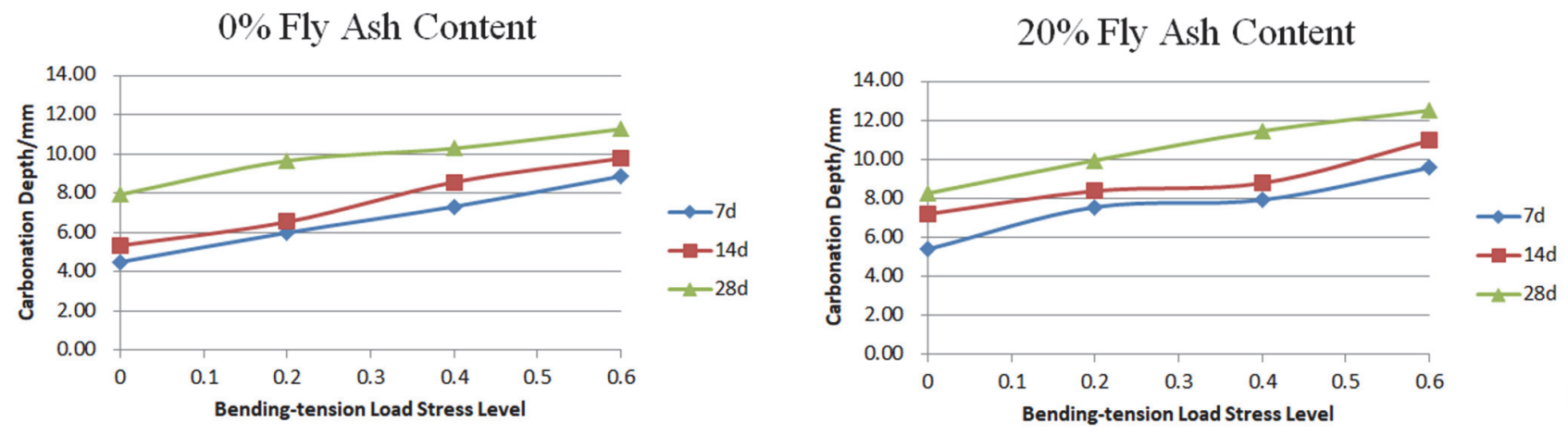

$30 \%$ Fly Ash Content
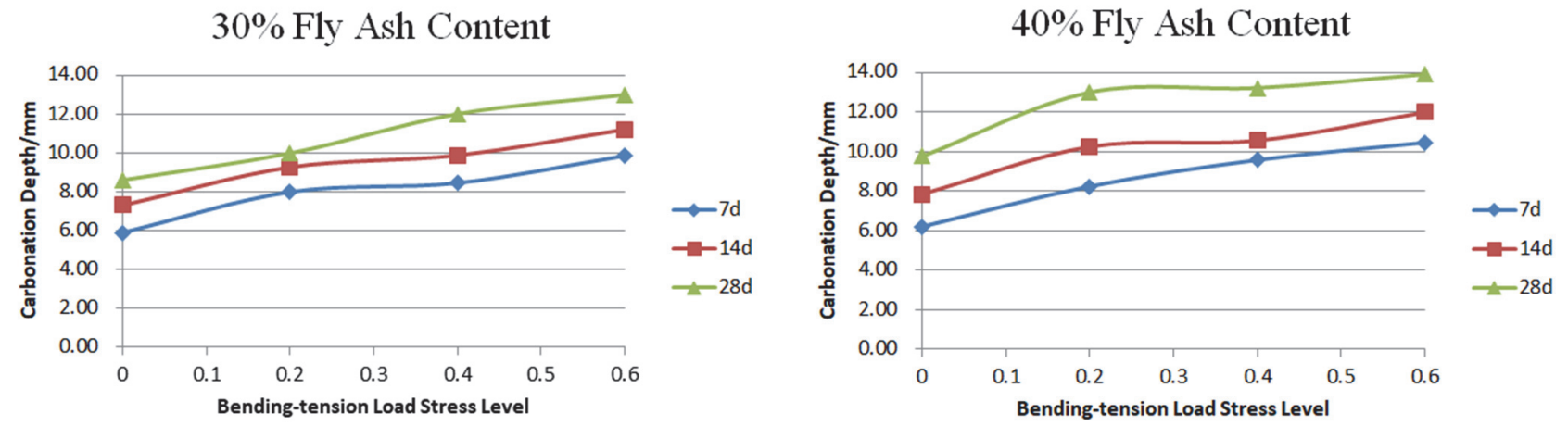

Figure 6: Relationship between carbonization depth in the concrete compression zone and bending-compression load stress level in different carbonation periods

\begin{tabular}{ccc}
\hline Fly ash content & Fitting equation & Correlation coefficient R \\
$0 \%$ & $K_{t}=1.0234 e^{0.9049 S_{t}}$ & 0.91 \\
$20 \%$ & $K_{t}=1.0266 e^{0.742 S_{t}}$ & 0.92 \\
$30 \%$ & $K_{t}=1.0356 e^{0.7268 S_{t}}$ & 0.95 \\
$40 \%$ & $K_{t}=1.0614 e^{0.683 S_{t}}$ & 0.91 \\
\hline
\end{tabular}

Table 5: Equation of the carbonization influence coefficient of bending-tension stress

Tab. 5 shows the exponential relationship between the carbonization influence coefficient of bending-tension stress and the bending load stress level, which is different from the results of the quadratic polynomial relationship in reference [16]. This is probably due to the fact that the test materials in the reference were plain concrete blocks and that the research did not consider the effect of steel bars.

\section{Carbonization influence coefficient of bending tension-compression load}

To study the relationship between the bending-compression zone and the bending-tension zone of the reinforced concrete block under bending loads, this paper analyzed and compared the different mechanical characteristics, crack development mechanisms and carbonization depths of the two zones under bending loads. 
There were a few initial micro-cracks and pores in the concrete, which were produced during the non-uniform shrinkage of coarse aggregate. These pores made $\mathrm{CO}_{2}$ penetrate the concrete and cause the carbonization damages of the concrete. When the reinforced concrete was subject to the bending load, cracks first appeared in the tension zone as the load increased. Meanwhile, the steel bar began to bear part of the tension force. $\mathrm{CO}_{2}$ mainly entered and eroded the inner part of the tension-zone of the concrete component along these cracks. With the increase of the bending load stress, the neutral axis of the block began to move towards the compression zone, and cracks appeared in the tension zone of the concrete. As the load further increased, the cracks became wider. This accelerated the erosion of the concrete by $\mathrm{CO}_{2}$ and thus increased the carbonization rate. There were still cracks below the neutral axis, but the tension force in the tensionzone is mainly borne by the steel bars. At this time, the compression stress in the compression zone also increased. With the further increase of pressure, the cracks and pores in the concrete were closed, hindering the diffusion of $\mathrm{CO}_{2}$ into the concrete and inhibiting the carbonization of concrete. However, the development of micro-cracks was very weak, and there was no macro change on the surface of the concrete. Therefore, the carbonization depth of concrete decreased as the load increased, but the change was relatively gentle.

As the bending stress further increased, the cracks in the tension-zone developed faster. As shown in Fig. 6, the slope of the curve and the carbonization damage to the concrete tension zone increased significantly under $40 \%-60 \%$ of the ultimate bending load. Meanwhile, under this load, an obvious crack was found in the middle span of the test block. This significant crack damage in the tension zone aggravated the diffusion of $\mathrm{CO}_{2}$ into the concrete to a greater extent and made the carbonization more serious. In addition, the curve declined more significantly under $40 \%-60 \%$ of the ultimate bending load, as shown in Fig. 5. When the strain in the compression zone increased, the concrete in this zone became more compact.

However, when the load exceeded a threshold, the tension steel bar began to yield, the cracks in the tension-zone expanded and went upwards, and the curve of the carbonization depth in this area increased more sharply. The rapid development of cracks led to the crush of the concrete in the compression zone. This made the $\mathrm{CO}_{2}$ erosion more rapid and aggravated the carbonization damage of the concrete.

To study the relationship between the bending-compression load and the bending-tension load with respect to their effects on the carbonization damage of reinforced concrete blocks, the ratio between the carbonization depth of the bending-compression zone and that of the bending-tension zone in the same block was fitted with the bending stress level, but no significant correlation was found. However, a more stable and accurate relationship between these two parameters was noticed, so the carbonization influence coefficient of bending tension-compression load is defined as follows:

$$
\mathrm{R}_{t-c}=\frac{X_{t}}{\operatorname{Ln}\left(X_{c}\right)}
$$

where $R_{t-c}$ is the carbonization influence coefficient of bending tension-compression load; $X_{t}$ the carbonization depth of concrete under the bending-tension load; and $X_{c}$, the carbonization depth of concrete under the bending-compression load.

The relationship between the carbonization influence coefficient of bending tension-compression load $K$ and the bending load stress level $S$ of reinforced concrete with different fly ash contents is shown in Tab. 6, where $R_{t c}$ is the carbonization influence coefficient of bending tension-compression load and $S$ is the bending load stress level.

\begin{tabular}{ccc}
\hline Fly ash content & Fitting equation & Correlation coefficient $\mathrm{R}$ \\
$0 \%$ & $\mathrm{R}_{t-c}=2.6657 S^{2}+4.6161 S+3.3387$ & 1.000 \\
$20 \%$ & $\mathrm{R}_{t-c}=2.0945 S^{2}+4.155 S+3.3189$ & 0.991 \\
$30 \%$ & $\mathrm{R}_{t-c}=0.5715 S^{2}+4.1445 S+3.3625$ & 0.998 \\
$40 \%$ & $\mathrm{R}_{t-c}=2.0666 S^{2}+5.2414 S+3.606$ & 0.988 \\
\hline
\end{tabular}

Table 6: Equation of the carbonization influence coefficient of bending tension-compression load

As shown in Tab. 6, there is a quadratic polynomial relationship between the carbonization influence coefficient of bending tension-compression load and the bending load stress level. In actual concrete engineering, some parts of the bending members are difficult to measure. By using the carbonization influence coefficient of bending tension- 
compression load proposed in this study, the carbonization damage degree of the lower part can be derived from the data obtained from the upper part of the block. This not only makes the operation easy but also ensures the accuracy of the data. However, it should be noted that the compression zone of the concrete will be crushed and nearly damaged under high pressure, which will show different carbonization performance from those in the study, so the carbonization influence coefficient is only applicable under $0 \%-60 \%$ of the ultimate bending load level.

\section{CONCLUSION}

I $\mathrm{n}$ this study, a long-term bending load device was developed to explore how the pouring surface and bending load affect the carbonization resistance of reinforced concrete under rapid carbonization. In addition, the relationship between the bending-tension and bending-compression loads with respect to their effects on the carbonization damage of test blocks was also investigated. The following conclusions are drawn:

(1) There is less coarse aggregate in the reinforced concrete pouring surface than at the same position in the bottom surface, with poorer compactness and lower carbonization resistance. The effect of the pouring surface is greater than that without fly ash on the carbonization resistance of fly ash concrete.

(2) When the fly ash content is constant, the bending-compression load has a significant effect on the carbonization of reinforced concrete blocks. The larger the bending load is, the smaller the carbonization depth will be. The carbonization influence coefficient of the bending-compression load and the bending load stress level follows a second-order polynomial relationship.

(3) When the fly ash content is constant, the bending-tension load has a significant effect on the carbonization of reinforced concrete blocks. The larger the bending load is, the greater the carbonization depth will be, which is typical under $40 \%-60 \%$ of the ultimate bending load. There is an exponential relationship between the carbonization influence coefficient of bending-tension load and the bending load stress level.

(4) The carbonization influence coefficient of bending tension-compression load of reinforced concrete under the bending load is defined. There is a second-order polynomial relationship between the carbonization influence coefficient of bending tension-compression load and the bending load stress level. In practical engineering, for those parts of the buildings that are difficult to measure, the degree of carbonization damage can be estimated using the carbonization influence coefficient. It provides scientific guidance for the detection and evaluation of carbonization damages in concrete structures.

\section{ACKNOWLEDGEMENTS}

7 his research is supported by Provincial Nature Science Foundation of Hebei Province: Study on concrete structure durability based on multi-factor coupling effect (NO. E2015204111) and Key Projects of Provincial Education Department of Hebei Province: Study on durability of existing concrete structures under loading (NO. ZD2016037) and Technology Foundation of Agricultural University of Hebei (No. LG201808).

\section{REFERENCE}

[1] Grzegorz, L.G. (2017). Improve of fracture toughness of green concrete as a result of addition of coal fly ash. Characterization of fly ash, Materials Characterization, 134, pp. 335-346.

[2] Harilal, M., Rathish, V.R., Anandkumar, B. (2019). High performance green concrete (HPGC)with improved strength and chloride ion penetration resistance by synergistic action of fly ash, nanoparticles and corrosion inhibitor, Construction and Building Materials, 198, pp. 299-312.

[3] Zheng, L., Xia, Z., Zhang, X.Y. (2018). Comparison between geopolymer reaction and cement hydration in solidification of fly ash generated in municipal solid waste incineration, Revue des Composites et des Matériaux Avancés, 28(3), pp. 395-403.

[4] Uthaman, S., Vishwakarma, V., George, R.P. (2018). Enhancement of strength and durability of fla ash concrete in seawater environments: Synergistic effect of nanoparticles, Construction and Building Materials, 187, pp. 448-459.

[5] Kurda, R., Silvestre, J.D., De Brito, J. (2018). Toxicity and environmental and economic performance of fly ash and recycled concrete aggregates use in concrete: A review, Heliyon, 4, pp. 38-45. 
[6] Zhang, H.N., Shen, C., Xi, P.S. (2018). Study on flexural properties of active magnesia carbonation concrete with fly ash content, Construction and Building Materials, 187, pp. 884-891.

[7] Branch, J.L., Epps, R., Kosson, D.S. (2018). The impact of carbonation on bulk and ITZ porosity in micro concrete materials with fly ash replacement, Cement and Concrete Research, 103, pp. 170-178.

[8] Atis, C.D. (2003). Accelerated carbonation and testing of concrete made with fly ash, Construction and Building Materials, 17(3), pp. 147-152.

[9] Wang, X., Wang, Y.B., Yang, L.S. (2017). Carbonation Resistance Property of the High Fly Ash Concrete, Construction and Building Materials, 138, pp. 486-494

[10] Kurda, R., De Brito, J., Slivestre, J.D. (2019). Carbonation of concrete made with high amount of fly ash and recycled concrete aggregates for utilization of CO2, Journal of CO2 Utilization, 29, pp. 12-19.

[11] Jiang, C., Gu, X.L., Zhang, W.P. (2015). Modeling of carbonation in tensile zone of plain concrete beams damaged by cyclic loading, Construct Build Mater, 77, pp. 479-488.

[12] Nwoji, C.U., Onah, H.N., Mama, B.O., Ike, C.C. (2018). Ritz variational method for bending of rectangular Kirchhoff plate under transverse hydrostatic load distribution, Mathematical Modelling of Engineering Problems, 5(1), pp. 1-10.

[13] Wang, J., Su, H., Du, J.S. (2018). Influence of coupled effects between flexural tensile stress and carbonation time on the carbonation depth of concrete, Construction and Building Materials, 190, pp. 439-451.

[14] Xi, S., Zhang, Y.Z., Ji, Y., Zhu, Y.L., Liu, Y., Yang, Y.T., Yu, M.L. (2018). Integrated growth of Si-O-C nanosheets on the surface of carbon microstructure with the aid of carbon nanotubes, Revue des Composites et des Matériaux Avancés, 28(2), pp. 289-298.

[15] Jiang, C., Gu, X., Zhang, W. (2015). Modeling of carbonation in tensile zone of plain concrete beams damaged by cyclic loading, Construction and Building Materials, 77, pp. 479-488.

[16] Niu, J.G. (2008). Study on Neutralization Performance of Concrete in the Atmospheric Environment Based on Multi-factor Effects, Xi'an University of Architecture and Technology.

[17] Liu, W.L. (2008). Research on Carbonation Rule of Fly Ash Concrete under Bending Loading and Environment, Xi'an University of Architecture and Technology.

[18] Zhang, Q.F. (2009). Study on Control Measures of Shrinkage Cracks in Concrete Structures, Concrete, (3), pp. 59-63.

[19] Daniel, J., Joseph, R., Prabakar, J., Alagusundaramoorthy, P. (2018). Flexural behavior of precast concrete sandwich panels under different loading conditions such as punching and bending, Cement and Concrete Research, 57(1), pp. 309-320.

[20] Falliano, D., De Domenico, D., Ricciardi, G. (2019). Compressive and flexural strength of fiber-reinforced foamed concrete: Effect of fiber content, curing conditions and dry density, Construction and Building Materials, 198, pp. 479-493.

[21] Ahmad, S., Sallam, Y., AI-Hawas, M. (2014). Effect of Key Factors on Compressive and Tensile Strength of Concrete Exposed to Elevated Temperatures, Arabian Journal for Science\& Engineering, 39(6), pp. 4507-4508.

[22] Francois, R., Maso, J.C. (1998). Effect of damage in reinforced concrete on carbonation or chloride penetration, Cement and Concrete Research, 18(6), pp. 961-970.

[23] Matsuda, K., Pa, P.S., Yun, W. (2014). Effect of Fiber Fraction on Compressive and Flexural Properties of HighStrength Fiber Reinforced Concrete, Applied Mechanics and Materials, 597, pp. 296-299.

[24] Chen, J., Song, X., Zhao, T. (2010). Service life prediction of lining concrete of subsea tunnel under combined compressive load and carbonation, Journal of Wuhan University of Technology-Master. Sci. Ed., 25(6), pp. 10611064.

[25] QC/T518-2013, Tightening Torque for Automotive Threaded Fasteners.

[26] Su, Y. (2017). Study on the Influence of Compaction on the Heterogeneity of Hardened Concrete, Harbin Institute of Technology.

[27] Barry, K.F., Biagini, M.S., Santamarina, J.C. (2013). Void Detection System for Fresh Concrete: USA, US2013192375A1, 2013-8-1.

[28] Chia, K., Kho, C., Zhang, M. (2005). Stability of Fresh Lightweight Aggregate Concrete under Vibration, ACI Material Journal, 102(5), pp.347-354.

[29] Banfill, P.F., Teixeira, M.A., Craik, R.J. (2011). Theology and Vibration of Fresh Concrete: Predicting the Radius of Action of Poker Vibrators from Wave Propagation, Cement and Concrete Research, 41(9), pp. 932-941.

[30] Navarrete, I., Lopez, M. (2016). Estimating the Segregation of Concrete Baser on Mixture Design and Vibratory Energy, Construction and Building Materials,122, pp. 384-390.

[31] Xie, Y.J., Chen, X.B. (2015). Effects of Fly Ash on Shearing Thinning and Thickening of Cement Paste, Journal of the Chinese Ceramic Society, 43(8), pp. 1041-1046. 